Article

\title{
Synthesis of Lanthanide-Functionalized Carbon Quantum Dots for Chemical Sensing and Photocatalytic Application
}

\author{
Fu-Ran Zou ${ }^{1,+}$, Sai-Nan Wang ${ }^{1,+}$, Fang-Fang Wang ${ }^{2,+}$, Dan Liu ${ }^{1}$ and Ying Li ${ }^{1, *(D)}$ \\ 1 School of Materials Science \& Engineering, University of Shanghai for Science and Technology, \\ Shanghai 200093, China; zoufuran_usst@163.com (F.-R.Z.); wangsainan@163.com (S.-N.W.); \\ ldanlucky@163.com (D.L.) \\ 2 The National Facility for Protein Science in Shanghai (NFPS), Shanghai 201210, China; \\ wangfangfang@sari.ac.cn \\ * Correspondence: liying@usst.edu.cn \\ + These authors contributed equally to this work.
}

Received: 19 June 2020; Accepted: 21 July 2020; Published: 24 July 2020

\begin{abstract}
Tunable photoluminescent-functionalized carbon quantum dots CQDs@Ln $(\mathrm{TFA})_{3}(\mathrm{Ln}=\mathrm{Eu}$, Tb; TFA: trifluoroacetylacetone) were designed and synthesized by introducing lanthanide complexes into the modified CQDs surface through the carboxyl group. The as-prepared CQDs@Ln (TFA) ${ }_{3}$ emit strong blue-green light with the peak at $435 \mathrm{~nm}$ and simultaneously show the characteristic emission of $\mathrm{Ln}^{3+}$ under irradiation of $365 \mathrm{~nm}$ light in aqueous solution. Moreover, these functionalized CQDs exhibit excellent photoluminescence properties. In addition, a white luminescent solution CQDs@Eu/Tb (TFA) $)_{3}$ was obtained by adjusting the ratio of $\mathrm{Eu}^{3+} / \mathrm{Tb}^{3+}$ and the excitation wavelengths. Moreover, CQDs@Tb (TFA) 3 can be utilized as a fluorescent probe for the sensitive and selective detection of $\mathrm{MnO}_{4}{ }^{-}$without interference from other ions in aqueous solution. These results provide the meaningful data for the multicomponent assembly and the photoluminescent-functionalized materials based on the modified CQDs and lanthanide, which can be expected to have potential application in photocatalytic or sensors.
\end{abstract}

Keywords: CQDs; lanthanide; chemical-sensing; photocatalytic properties

\section{Introduction}

As a new member of carbonaceous nanomaterials including carbon nanotubes, graphene and carbon quantum dots (CQDs), owing to the superior chemical and electrical properties, high photostability, as well as excellent biocompatibility, CQDs have attracted broad interest from scientific and industrial community [1-5]. In the past few years, CQDs have been used as a green alternative to organic dyes and conventional semiconductor quantum dots due to their applications in versatile fields, such as bioimaging [6-10], drug delivery [11-13], optronics [14-16], catalysis [17-19], photocatalytic [20], chemical sensors [21-24] and other aspects [25-27]. In recent years, research on CQDs with single excitation wavelength has gradually matured. In particular, blue carbon quantum dots have been prepared in large quantities - and can even be produced in batches-of which the quantum yield is even higher than 75\% [28-30]. Research on different photoluminescence and photocatalysis property of carbon quantum dots has also matured and stabilized [31-39]. Even the micromorphology control of carbon quantum dots has made great progress, such as triangular carbon quantum dots [40-42]. However, the quantification of determining the detection object by only the intensity change of a single peak will be affected by the surrounding environment and the instrument itself. Carbon quantum dot-based proportional dual-emission fluorescence can not only improve its 
sensitivity, but also avoid interference from the detection background. Therefore, it is more interesting to explore the application of quantum dots in proportional dual-emission fluorescence. Since non-single fluorescence color changes are more perceptible by the naked eye, they are useful for semi-quantitative monitoring of substances [43-45].

It is well known that lanthanide (III) $\beta$-diketonate complexes are excellent luminescent materials with distinct emission bands, long lifetime as well as high quantum efficiency. The $\mathrm{Ln}^{3+}$ emission arises from $4 \mathrm{f}-4 \mathrm{f}$ electronic transition. Among these, $\mathrm{Eu}^{3+}$ and $\mathrm{Tb}^{3+}$ can, respectively, emit pure red and green light in almost any environment, free of the influence of external factors due to their light emission originating from the electron redistribution of the $4 \mathrm{f}$ orbital, which is effectively shielded by the overlying $5 s^{2}$ and $5 p^{6}$ orbital. Therefore, modification of CQDs with a high-luminescence lanthanide complex is an important method to fabricate excellent composites that exhibit superior properties to the individual components. CQDs contain many carboxylic acid moieties at their surface that may combine with the lanthanide ions. In addition, whether white emission can be achieved by taking CQDs as blue emitter and incorporating with lanthanide complexes is worth to be further studied. Lanthanide ions can be introduced into the surface of CQDs to obtain a dual-emission fluorescent composite material due to the tunable fluorescence wavelength, excellent light absorption and light emission capabilities of CQDs. In addition, the excellent dual-emission fluorescent performance depends on the effective photoelectron energy transfer (PET) progress from organic ligand to the central ions, which can reduce the errors caused by spectral overlap between each other. Actually, CQDs can be used as both a photocatalysis material and a photosensitizer for the lanthanide element in the lanthanide-functionalized carbon quantum dot dual-emission fluorescent composite material. In recent years, designing lanthanide complex functionalized carbon quantum dots has been an important direction in chemistry research and photocatalytic fields; it is also an extension of the properties of lanthanide complexes and monofunctional carbon nanomaterials. Furthermore, the tunable photoluminescent and photocatalytic properties of the functionalized CQD have drawn increased attention to carbon nanomaterials and the methods of modifying CQDS for photocatalytic applications mainly include surface functionalization, passivation, element doping and composite synthesis.

Herein, we have developed a simple and an effective strategy to design a novel lanthanide functionalized dual-emission fluorescent material CQDs@Ln(TFA) $)_{3}(\mathrm{Ln}=\mathrm{Eu}, \mathrm{Tb}$; TFA: trifluoroacetylacetone) via introducing Ln (TFA) 3 into the surface of CQDs with the carboxyl group. (Scheme 1) The obtained CQDs@Ln (TFA) 3 exhibited great photoluminescent and chemical-sensing properties. It is because of the characteristic emission of CQDs@Eu/Tb(TFA $)_{3}$, the intense white emission with the chromaticity diagram coordinates $(\mathrm{CIE}=(0.32,0.27))$ can be obtained by adjusting the ratio of $\mathrm{Eu}^{3+} / \mathrm{Tb}^{3+}$. On account of the strong green light intensity of CQDs@Tb(TFA) 3 , it can be used to selectively and sensitively detect $\mathrm{MnO}_{4}{ }^{-}$in aqueous solution. The results show that CQDs@Ln(TFA) 3 have potential applications in environmental and photocatalytic chemistry fields. The effects of CQDs size and functionalization on photocatalytic properties are the important factors on the photocatalytic applications of CQDs in water splitting, hydrogen evolution, water treatment and chemical degradation, etc. 

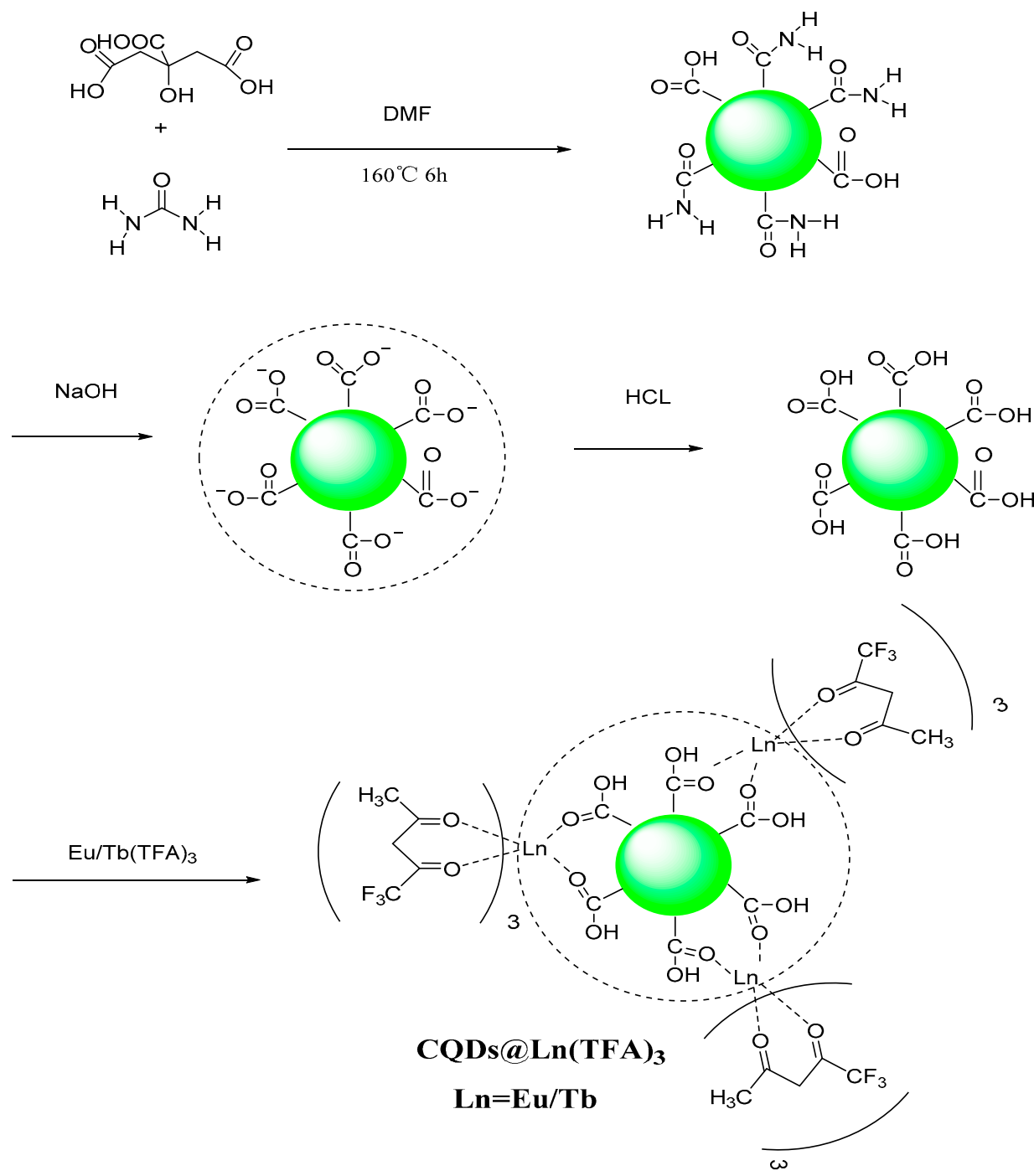

Scheme 1. Schematic representation and diagram of CQDs@Ln (TFA) 3.

\section{Results and Discussion}

\subsection{Preparation and Structural Characterization of CQDs and CQDs@Ln $(T F A)_{3}(\operatorname{Ln}=E u, T b)$}

CQDs were successful prepared by a hydrothermal method and confirmed by the TEM images (Figure 1a), which revealed that the CQDs were uniform nanoparticles with an average size about $2.5 \mathrm{~nm}$ with a standard deviation of $\pm 0.45 \mathrm{~nm}$. Furthermore, HRTEM image (Figure $1 \mathrm{~b}$ ) shows that the CQDs have certain crystal structure with average lattices spacing about $0.23 \mathrm{~nm}$ and there is a uniform dispersion without apparent aggregation.

The fluorescence spectrum displays the emission of CQDs at different excitation wavelengths ranging from 340 to $500 \mathrm{~nm}$ and the observation reveals that the CQDs show typical wavelength-dependent photoluminescence behavior in aqueous solution (Figure 2a). It can be obviously observed the changes in emission wavelength and intensity with respect to the excitation wavelength due to the different surface states and size dispersion of the carbon nanoparticles. The strongest fluorescence emission band, located at $448 \mathrm{~nm}$ is also observed under $365 \mathrm{~nm}$ excitation, which shows blue-green fluorescence under UV light (Figure 2b). In addition, the aqueous solution of CQDs presents bright yellow photoluminescence centered at $540 \mathrm{~nm}$ in the emission spectrum under the excitation wavelength of $450 \mathrm{~nm}$ in Figure S1. 

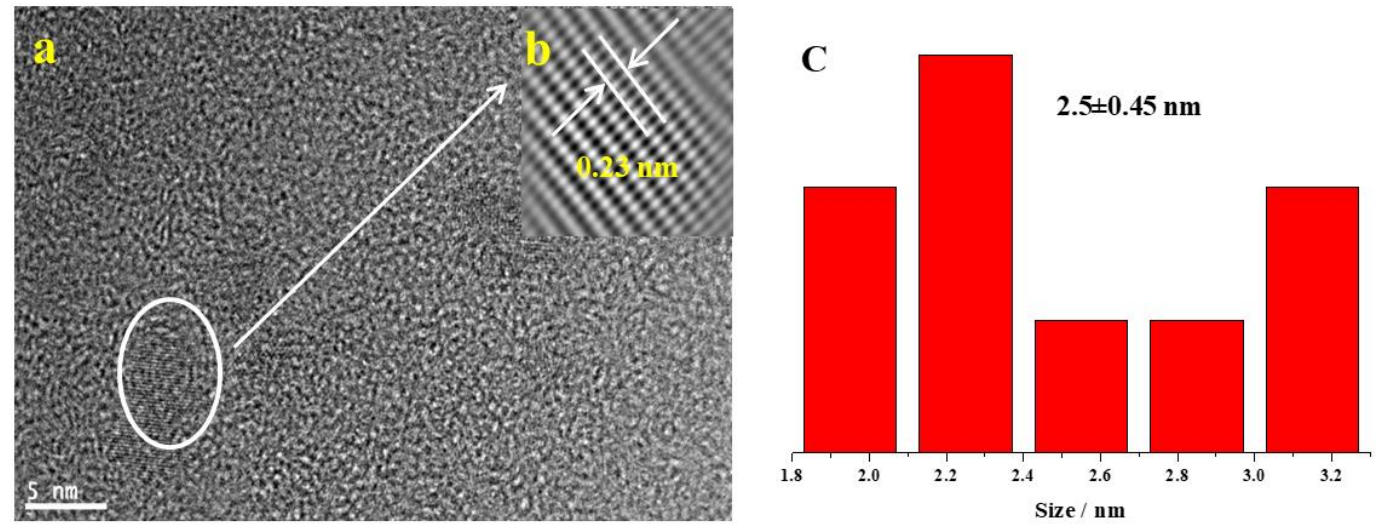

Figure 1. (a) TEM and (b) HRTEM images of carbon quantum dots (CQDs); (c) particle-size distribution of CQDs.
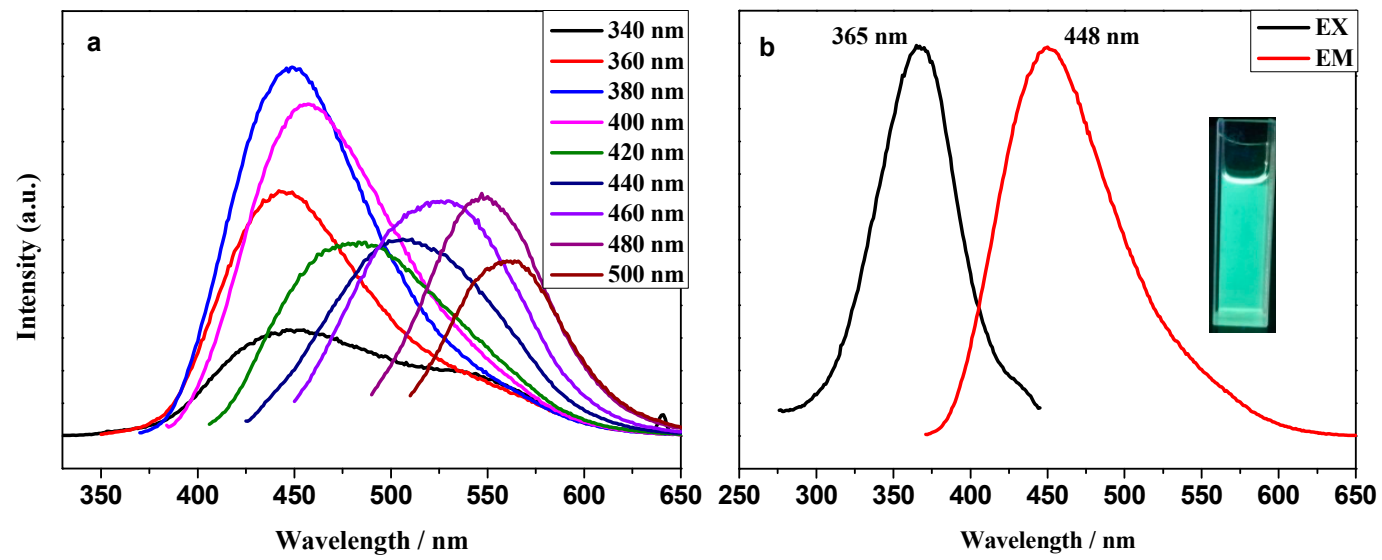

Figure 2. (a) PL emission spectrum of CQDs with different wavelengths; (b) Excitation (EX) and emission (EM) spectrum of CQDs in aqueous solution.

CQDs@Ln (TFA) $)_{3}$ were successfully synthesized by introducing the unsaturated lanthanide complex $\mathrm{Ln}(\mathrm{TFA})_{3}(\mathrm{Ln}=\mathrm{Tb}, \mathrm{Eu})$ into the surface of CQDs via coordinated band (Scheme 1). The characteristic peaks of FTIR spectroscopy (Figure 3) disappeared at about $1643 \mathrm{~cm}^{-1}(-\mathrm{C}=\mathrm{O})$, indicating the CQDs had combined with the $\mathrm{Ln}(\mathrm{TFA})_{3}(\mathrm{Ln}=\mathrm{Tb}, \mathrm{Eu})$. Compared with CQDs@Tb $(\mathrm{TFA})_{3}$, it can be clearly seen that the blue-shift from $315 \mathrm{~nm}$ to $343 \mathrm{~nm}$, attributing to $\mathrm{n}-\pi^{*}$ transition of $-\mathrm{C}=\mathrm{O}$. The blue-shift increases the $\pi^{*}$ energy of the whole system due to the coordination between CQDs and lanthanide complexes. (Figure 4) In addition, the characteristic peaks of Eu3d (1135.68 ev) and Tb3d (1242.46 ev) can be observed in the XPS spectrum. (Figure S2a). Compared to the pure CQDs (531.5 ev), the O1 s (Figure S2b) of CQDs@Tb (TFA) 3 composite (532.4 ev) has a higher binding energy, which can be attributed to the formation of ground state complexes between carboxyl groups on the surface of CQDs and rare earth ions, resulting in a decrease in the electron density of $\mathrm{O}$ atoms [46]. In order to further confirm the crystal structure of the composite material, we made Raman spectra of CQDs and CQDs@Tb (TFA) 3 (Figure S3). It can also be observed that the D peak disappeared in CQDs@Tb (TFA) $)_{3}$ and the $G$ peak becomes sharp after the carboxyl coordination, indicating CQDs@Tb $(\mathrm{TFA})_{3}$ still has a crystalline structure. All the above experimental results confirmed the successful synthesis of CQD@Ln (TFA) ${ }_{3}$, and the surface functionalization did not change the crystal structure of CQDs. 


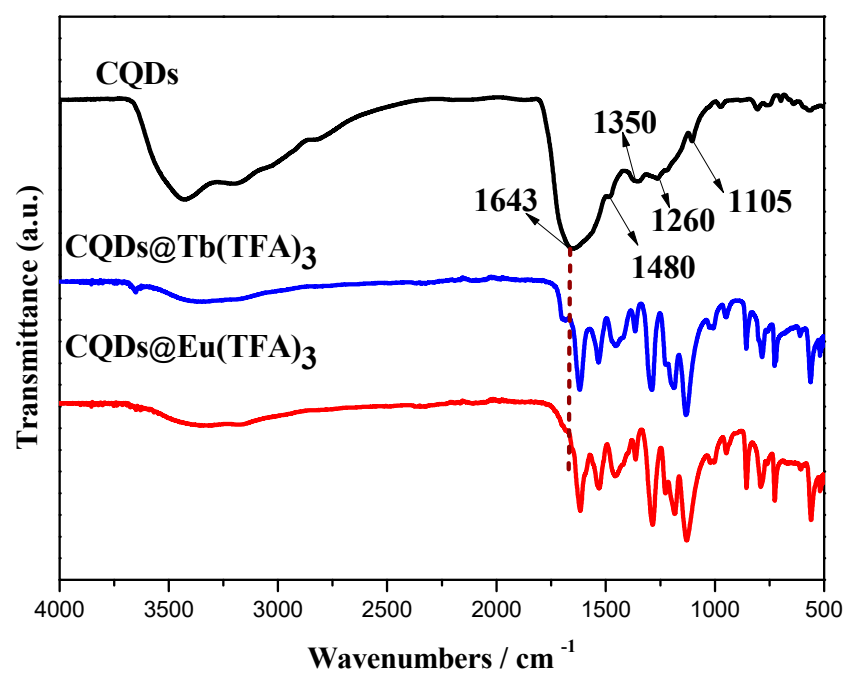

Figure 3. FTIR spectra of CQDs and CQDs@Ln (TFA) $3(\mathrm{Ln}=\mathrm{Eu}, \mathrm{Tb})$ composites.

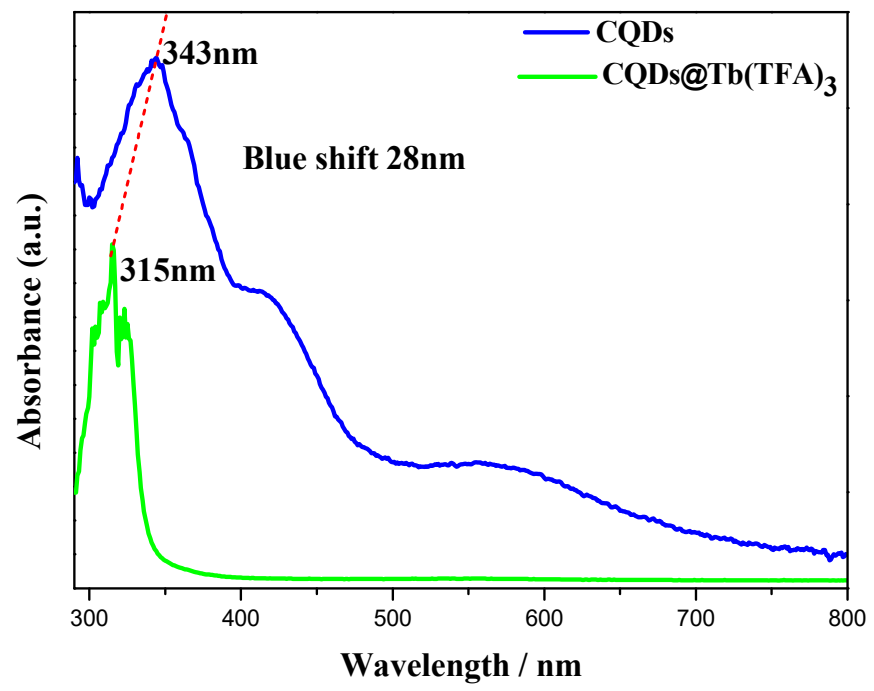

Figure 4. UV-Vis absorption spectra of CQDs and CQDs@Ln (TFA) $)_{3}(\mathrm{Ln}=\mathrm{Eu}, \mathrm{Tb})$.

\subsection{Photoluminescence Properties and Chemical Sensing Performance of CQDs@Ln $(T F A)_{3}$}

The luminescence properties of CQDs@Ln (TFA) $)_{3}$ were measured at room temperature in detail. The emission spectra of CQDs@Eu (TFA) ${ }_{3}$ (a) and CQDs@Tb (TFA) 3 (b) are mainly obtained to display

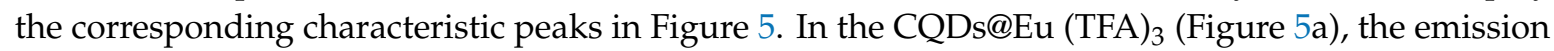
spectrum shows four sharp peaks located at 580,591, 613 and $652 \mathrm{~nm}$, which can be assigned to ${ }^{5} \mathrm{D}_{0} \rightarrow{ }^{7} \mathrm{~F}_{\mathrm{J}}(\mathrm{J}=0-3)$ transitions of Eu ${ }^{3+}$, respectively [47,48]. As can be clearly seen that the emission spectra of CQDs@Eu (TFA) $)_{3}$ are dominated by the intense ${ }^{5} \mathrm{D}_{0} \rightarrow{ }^{7} \mathrm{~F}_{2}$ transition at $613 \mathrm{~nm}$ and the peak centered at $544 \mathrm{~nm}$ comes from ${ }^{5} \mathrm{D}_{4} \rightarrow{ }^{7} \mathrm{~F}_{5}$ of $\mathrm{Tb}^{3+}$ in CQDs@Tb (TFA) 3 . The peak in the range of 380-500 nm originated from the CQDs and the emission band of CQDs in the CQDs@Ln (TFA) ${ }_{3}$ is centered at about $435 \mathrm{~nm}$. The dual-emitting fluorescent composite is not only a change from "one" to "two", but simplifies the design of CQDs proportional sensing and expands corresponding applications. 


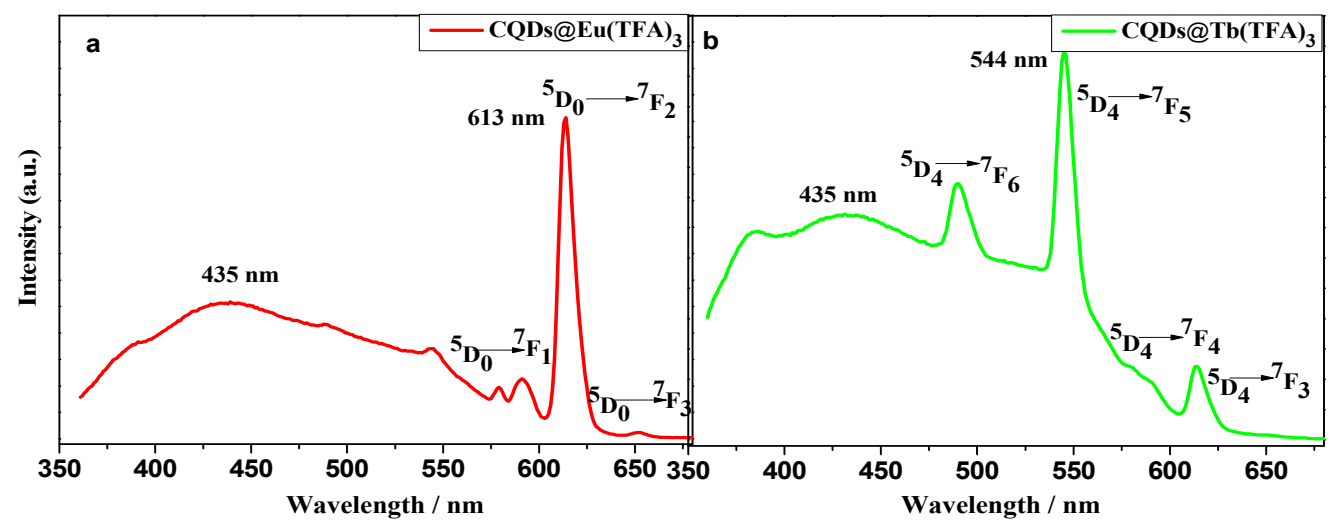

Figure 5. The emission spectra of CQDs@Eu(TFA) $)_{3}(\mathbf{a})$ and CQDs@Tb(TFA) 3 (b).

$\mathrm{MnO}_{4}{ }^{-}$is commonly used as a disinfectant in agricultural and plays an important role in medicine and health. However, $\mathrm{MnO}_{4}{ }^{-}$with high concentration will increase the ecological risk [49]. Therefore, identifications of these solution and ions are of great importance in the life. To identify the selective fluorescence sensing of anion ions by the CQDs@ $@ b(\mathrm{TFA})_{3}$, the quenching performance was carried out in the presence of different anion ions with a concentration of $10^{-3} \mathrm{M}$ at $365 \mathrm{~nm}$ excitation wavelength. Figure 6 shows PL emission spectra of CQDs@Tb $(\mathrm{TFA})_{3}$ in the presence of various anion ions including $\mathrm{CO}_{3}{ }^{2-}, \mathrm{NO}_{3}{ }^{-}, \mathrm{S}_{2} \mathrm{O}_{8}{ }^{2-}, \mathrm{SO}_{4}{ }^{2-}, \mathrm{I}^{-}, \mathrm{Br}^{-}, \mathrm{Cl}^{-}, \mathrm{CrO}_{4}{ }^{2-}, \mathrm{Cr}_{2} \mathrm{O}_{7}{ }^{2-}$ and $\mathrm{MnO}_{4}{ }^{-}$under $\lambda_{\text {ex }}=365 \mathrm{~nm}$ and the corresponding anion bar graph $\left(\mathrm{I}_{\mathrm{CQD} /} / \mathrm{I}_{\mathrm{Tb}}\right)$ are shown in illustration. The luminescent intensity of the characterization of $\mathrm{Tb}^{3+}$ can clarify the effect of the chemical-sensing. The peak centered at $545 \mathrm{~nm}$ is ascribed to the ${ }^{5} \mathrm{D}_{4} \rightarrow{ }^{7} \mathrm{~F}_{5}$ of $\mathrm{Tb}^{3+}$ ions and the green emission is weakened with different anions (Figure 6) Furthermore, it is obviously observed that $\mathrm{MnO}_{4}{ }^{-}$quenches the intensity notably. Comparing the fluorescence intensity ratio $\left(\mathrm{I}_{\mathrm{CQDs}} / \mathrm{I}_{\mathrm{Tb}}\right)$ of the double emission peaks of each anion, it was observed that the value of $\mathrm{I}_{\mathrm{CQDs}} / \mathrm{I}_{\mathrm{Tb}}$ was the lowest when $\mathrm{MnO}_{4}{ }^{-}$present. Therefore, it can be vividly demonstrated that the CQDs@Tb (TFA) ${ }_{3}$ fluorescent sensor was highly selective towards $\mathrm{MnO}_{4}{ }^{-}$over the other anion ions.

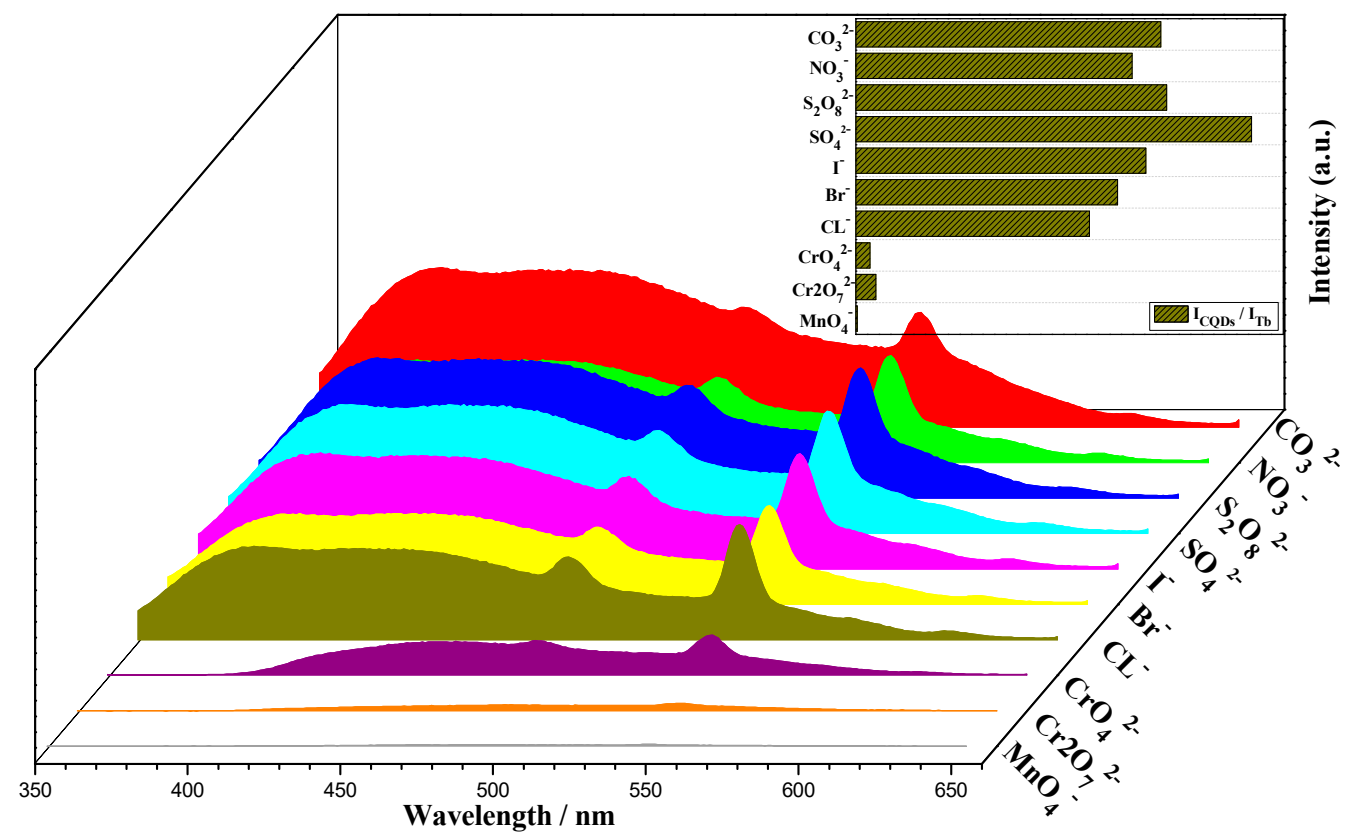

Figure 6. PL emission spectrum of CQDs@Tb $(\mathrm{TFA})_{3}$ in the presence of various anions (The illustration is a histogram of $\mathrm{I}_{\mathrm{CQDs}} / \mathrm{I}_{\mathrm{Tb}}$ ). 
Similarly, in order to explore whether other anions would interfere with the detected $\mathrm{CrO}_{4}{ }^{2-}$, $\mathrm{Cr}_{2} \mathrm{O}_{7}{ }^{2-}$ and $\mathrm{MnO}_{4}{ }^{-}$, we also conducted fluorescence interference experiments on the $\mathrm{CrO}_{4}{ }^{2-}$, $\mathrm{Cr}_{2} \mathrm{O}_{7}{ }^{2-}$ and $\mathrm{MnO}_{4}{ }^{-}$anions. The experimental results are shown in Figure $\mathrm{S} 4$. The results show that the other anions have almost no interference with the change of the fluorescence intensity of $\mathrm{CrO}_{4}{ }^{2-}$, $\mathrm{Cr}_{2} \mathrm{O}_{7}{ }^{2-}$ and $\mathrm{MnO}_{4}{ }^{-}$anions, indicating that the CQDs@Tb (TFA) $)_{3}$ composite will be a valuable tool for the detection of $\mathrm{MnO}_{4}{ }^{-}$.

To further explore the sensitivity of $\mathrm{CrO}_{4}{ }^{2-}, \mathrm{Cr}_{2} \mathrm{O}_{7}{ }^{2-}$ and $\mathrm{MnO}_{4}{ }^{-}$, we studied the fluorescence intensity changes of CQDs@Tb (TFA) $)_{3}$ in the presence of different concentrations of $\mathrm{CrO}_{4}{ }^{2-}, \mathrm{Cr}_{2} \mathrm{O}_{7}{ }^{2-}$ and $\mathrm{MnO}_{4}{ }^{-}$ions. The luminescent intensity of CQDs@Tb(TFA) ${ }_{3}$ can be obtained with the concentration range of anion from 0 to $50 \mu \mathrm{M}$. (Figure 7a) As shown in Figure $7 \mathrm{~b}$, the ratio $\left(\mathrm{I}_{\mathrm{CQDs}} / \mathrm{I}_{\mathrm{Tb}}\right)$ of the CQDs@ $@ \mathrm{~Tb}$ $(\mathrm{TFA})_{3}$ gradually decreases with increasing the $\mathrm{MnO}_{4}{ }^{-}$ion concentration in solution. Meanwhile, Figures 8a and 9a display the emission spectrum of $\mathrm{CrO}_{4}{ }^{2-}$ and $\mathrm{Cr}_{2} \mathrm{O}_{7}{ }^{2-}$ in the concentration 0-50 $\mu \mathrm{M}$. Furthermore, the value of $\mathrm{I}_{\mathrm{CQDs}} / \mathrm{I}_{\mathrm{Tb}}$ is linearly related to the concentration of $\mathrm{MnO}_{4}{ }^{-}$in the range of $0-50 \mu \mathrm{M}$ and the limit of detection (LOD) was determined to be as low as $0.55 \mu \mathrm{M}$, implying that CQDs@Tb (TFA) $)_{3}$ composite can be used for selective detection of $\mathrm{MnO}_{4}{ }^{-}$ion as a ratiometric fluorescent molecular probe. In addition, the results of comparison with some other methods for the detection of $\mathrm{MnO}_{4}{ }^{-}$are listed in Table 1. It can be seen that the LOD of this method is comparable or lower than some other reported methods [50,51]. The LOD of $\mathrm{CrO}_{4}{ }^{2-}, \mathrm{Cr}_{2} \mathrm{O}_{7}{ }^{2-}$ and $\mathrm{MnO}_{4}{ }^{-}$can be calculated as follows:

$$
\begin{gathered}
\sigma=\sqrt{\frac{\sum\left(I_{0}-I_{1}\right)^{2}}{n-1}} \\
\mathrm{LOD}=3 \sigma / s
\end{gathered}
$$

where $\sigma$ is the standard deviation of the repeated detection blank solution $(\mathrm{N}=30) ; \mathrm{I}_{1}$ is the dual fluorescence intensity ratio ( $\mathrm{I}_{\mathrm{CQDs}} / \mathrm{I}_{\mathrm{Tb}}$ ) of CQDs@ $\mathrm{Tb}(\mathrm{TFA})_{3}$ in water; $\mathrm{I}_{0}$ is the average value of $\mathrm{I}_{\mathrm{CQDs}} / \mathrm{I}_{\mathrm{Tb}}$; $\mathrm{S}$ is slope of the linear curve [49]. Moreover, CQDs@Eu (TFA) $)_{3}$ has the same fluorescence properties as CQDs@Tb (TFA) 3 . As shown in Figure S5, CQDs@Eu (TFA) 3 was used as a fluorescent probe to detect $\mathrm{MnO}_{4}{ }^{-}$(concentration within 0-50 $\mu \mathrm{M}$ ). Obviously, the ratio of the intensity ( $\mathrm{I}_{\mathrm{CQDs}} / \mathrm{I}_{\mathrm{Eu}}$ ) of CQDs@Eu (TFA) ${ }_{3}$-with the solution concentration of $\mathrm{MnO}_{4}{ }^{-}$ion gradually decreases, and the value of $\mathrm{I}_{\mathrm{CQDs}} / \mathrm{I}_{\mathrm{Eu}}$ is linearly related to the concentration of $\mathrm{MnO}_{4}{ }^{-}$in the range of $0-50 \mu \mathrm{M}$, and the detection limit (LOD) is determined to be as low as $0.37 \mu \mathrm{M}$, which is relatively more sensitive than the CQDs@Tb (TFA) $)_{3}$ composite.
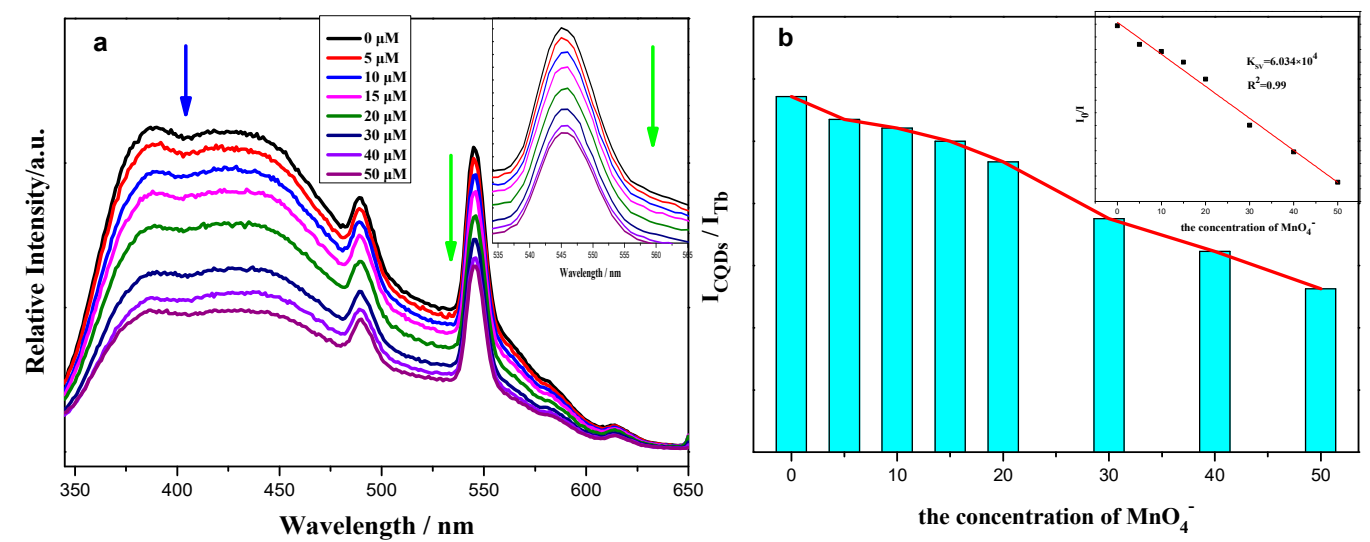

Figure 7. (a)The luminescent intensity of CQDs@ $\mathrm{Tb}(\mathrm{TFA})_{3}$ with the different concentration of $\mathrm{MnO}_{4}{ }^{-}$ (b) $\mathrm{I}_{\mathrm{CQDs}} / \mathrm{I}_{\mathrm{Tb}}$ of CQDs@Tb(TFA) $)_{3}$ with the solution concentration of $\mathrm{MnO}_{4}{ }^{-}$. 

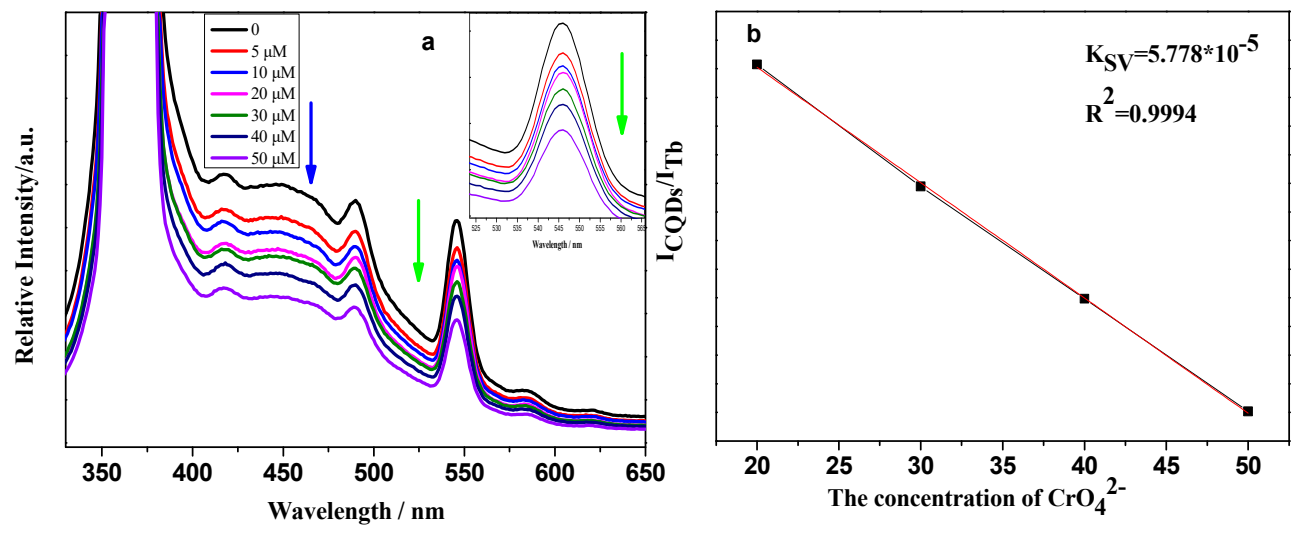

Figure 8. (a)The luminescent intensity of $\mathrm{CQDs} @ \mathrm{~Tb}(\mathrm{TFA})_{3}$ with the different concentration of $\mathrm{CrO}_{4}{ }^{2-}$ (b) $\mathrm{I}_{\mathrm{CQDs}} / \mathrm{I}_{\mathrm{Eu}}$ of CQDs@Eu (TFA) 3 with the solution concentration of $\mathrm{CrO}_{4}{ }^{2-}$.
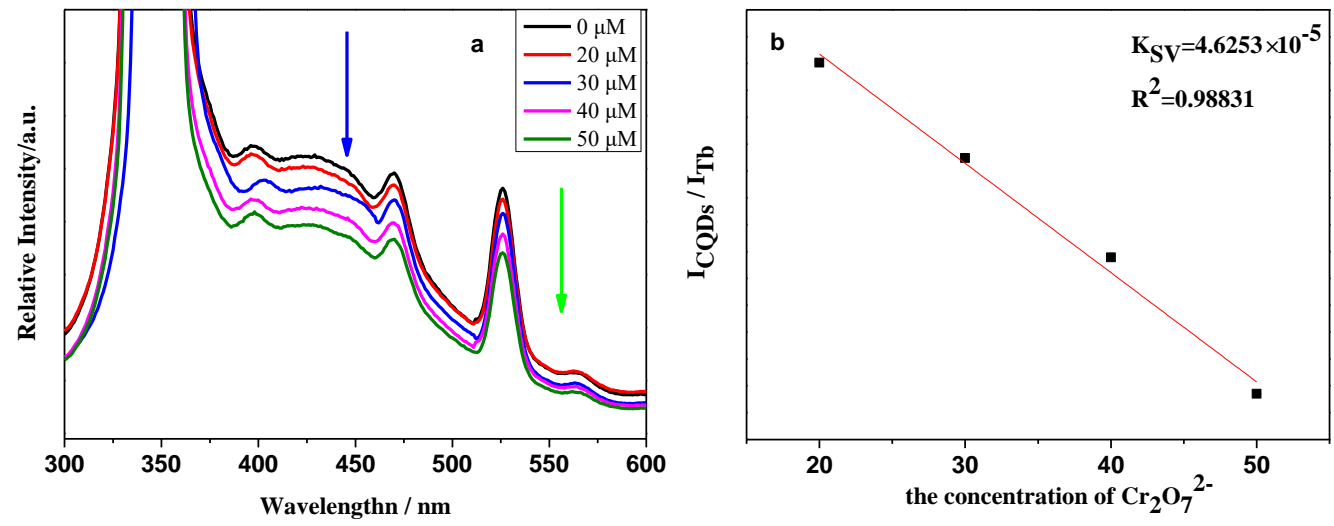

Figure 9. (a)The luminescent intensity of CQDs@Tb(TFA) $)_{3}$ with the different concentration ofCr $\mathrm{O}_{7}{ }^{2-}$; (b) $\mathrm{I}_{\mathrm{CQDs}} / \mathrm{I}_{\mathrm{Eu}}$ of CQDs@Eu (TFA) $)_{3}$ with the solution concentration of $\mathrm{Cr}_{2} \mathrm{O}_{7}{ }^{2-}$.

Table 1. Sensing properties of different types of $\mathrm{MnO}_{4}{ }^{-}$detection.

\begin{tabular}{cccc}
\hline Detection Method & Linear Range $(\mu \mathrm{M})$ & Detection Limit & Ref. \\
\hline n-MOF-Eu & $0-500$ & $1.47 \mu \mathrm{M}$ & {$[49]$} \\
$\mathrm{Cd}(\mathrm{HL})\left(4,4^{\prime}\right.$-bipy) & $40-100$ & $0.647 \mu \mathrm{M}$ & {$[50]$} \\
I [Eu(DLDA)(DMF)(H $\left.\left.\mathrm{H}_{2} \mathrm{O}\right)(\mathrm{COO})\right]_{\mathrm{n}}$ & $0-200$ & $10.8 \mu \mathrm{M}$ & {$[51]$} \\
CQDs@Tb(TFA) $)_{3}$ & $0-476$ & $1.43 \mu \mathrm{M}$ & {$[52]$} \\
A dual-responsive Luminescent Terbium(III) Chain & $0-50$ & $0.55 \mu \mathrm{M}$ & This work \\
\hline
\end{tabular}

There are two possible reasons for the quenching mechanism of CQDs@Ln $(\mathrm{TFA})_{3}(\mathrm{Ln}=\mathrm{Eu}, \mathrm{Tb})$ by $\mathrm{MnO}_{4}^{-}$: First, there is overlap between the excitation of the composite material and the absorption of $\mathrm{MnO}_{4}{ }^{-}$. That is, the excitation and adsorption energy competition between $\mathrm{Tb}^{3+}$ and $\mathrm{MnO}_{4}^{-}$may cause fluorescence quenching, and CQDs accelerate the energy competition process [49] and further lead to the fluorescence quenching of CQDs@Ln (TFA) $)_{3}$. Second, we suspect that $\mathrm{MnO}_{4}{ }^{-}$initially reacted with CQDs, resulting in the formation of $\mathrm{MnO}_{2}$, and $\mathrm{Mn}$ element adhered to the surface of the composite to form a ground state complex, which accelerated the interaction between $\mathrm{MnO}_{4}{ }^{-}$and $\mathrm{Ln}^{3+}$, which ultimately led to fluorescence quenched of CQDs@Ln (TFA) 3 . This result will provide a new possibility to be applied in the photocatalysis field.

\subsection{White-Light Tuning of CQDs@Eu/Tb (TFA)}

Considering that the blue-green light of CQDs, red light of $\mathrm{Eu}^{3+}$ and green light of $\mathrm{Tb}^{3+}$ as light emission centers, respectively, the tunable white emission in CQDs@Eu/Tb (TFA) ${ }_{3}$ can be obtained by adjusting the proportion of $\mathrm{Eu}^{3+} / \mathrm{Tb}^{3+}$. The emission spectrum of CQDs@Eu/Tb $(\mathrm{TFA})_{3}$ and the 
corresponding CIE chromaticity diagram under the excitation wavelengths (340-365 nm)was given in Figure 10. The photoluminescence color of CQDs@Eu/ $\mathrm{Tb}(\mathrm{TFA})_{3}\left(\mathrm{Eu}^{3+}: \mathrm{Tb}^{3+}=1: 1\right)$ can be tuned from white to blue by changing the excitation wavelength from $340 \mathrm{~nm}$ to $365 \mathrm{~nm}$. In addition, Figure 11 shows the emission spectrum of CQDs@Eu/Tb (TFA) $)_{3}$ in different ratios of $\mathrm{Eu}(\mathrm{TFA})_{3}: \mathrm{Tb}(\mathrm{TFA})_{3}$ at the same excitation wavelength of $350 \mathrm{~nm}$. It is interesting that the white emission is located at CIE region $(x=0.32$ and $y=0.27)$ when excited with the same $350 \mathrm{~nm}$ laser. In summary, we can obtain white luminescence by adjusting the fluorescence emission spectra of CQDs@Eu/Tb $(\mathrm{TFA})_{3}$ at different excitation wavelengths when the ratio of lanthanide ions fixed and when the ratio of lanthanide ions different at the same excitation wavelength.

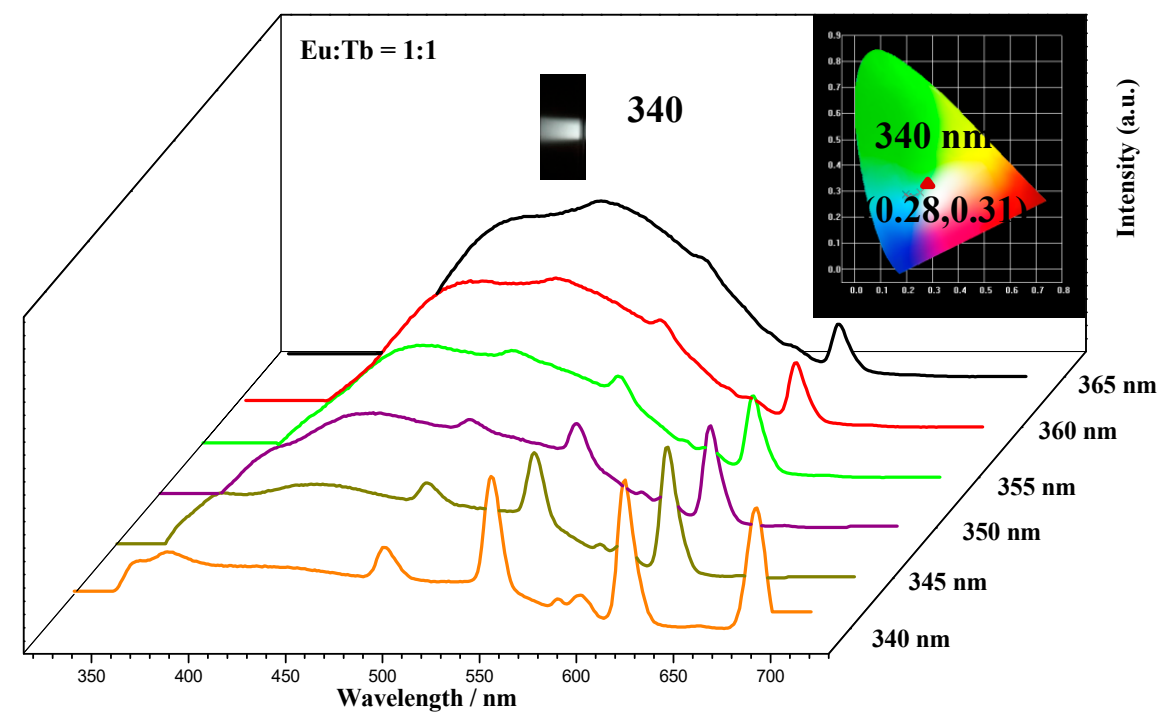

Figure 10. Emission spectra and corresponding chromaticity diagram coordinates (CIE) at different excitation wavelengths.

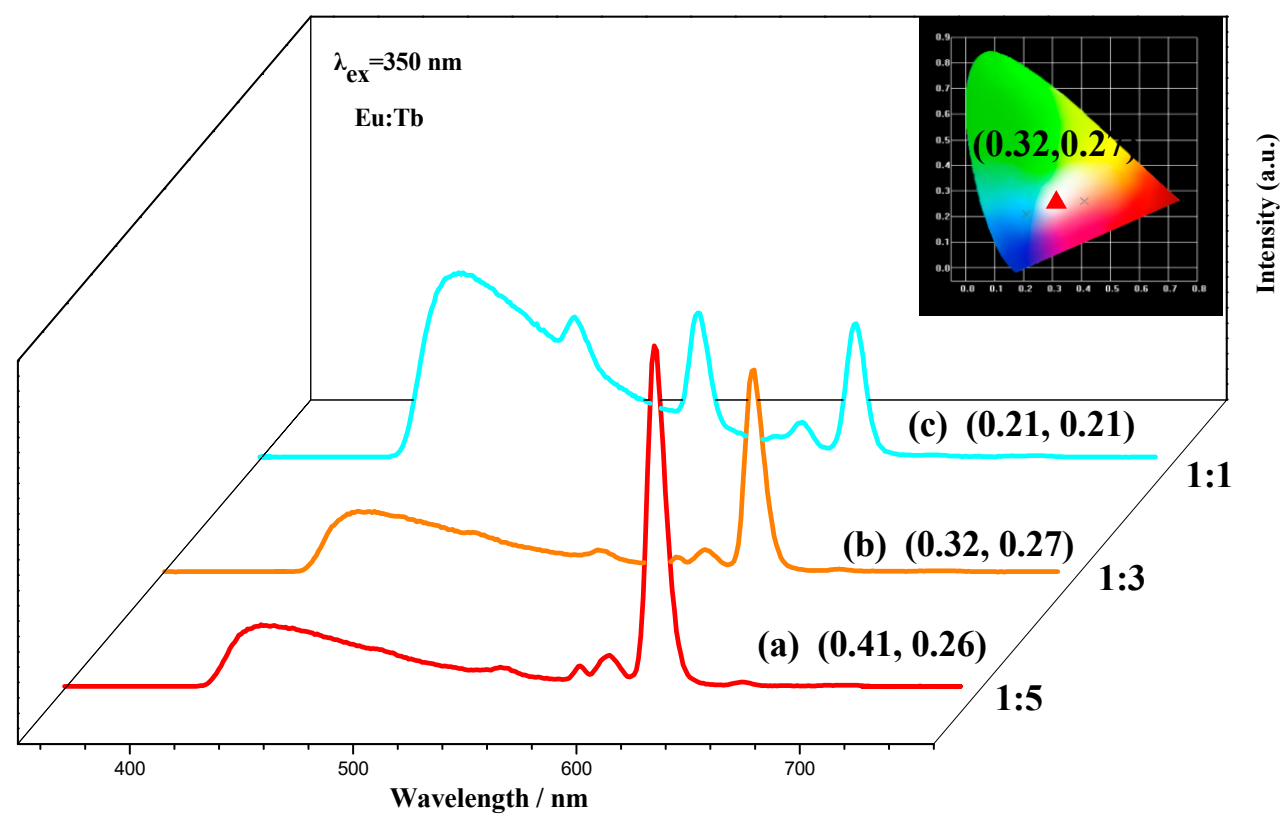

Figure 11. Photoluminescence (PL) spectra and corresponding CIE coordinates at $\lambda_{\mathrm{ex}}=350 \mathrm{~nm}$. 


\section{Materials and Methods}

\subsection{Materials}

Citric acid, urea, $\mathrm{NaOH}$ and $\mathrm{HCl}$ all the other reagents purchased from Aladdin Industrial Corporation (Shanghai, China), were all used directly in the as-received condition without further purification.

\subsection{Characterization}

Photoluminescence (PL) emission measurements were performed using RF-5301 PC spectrophotometer with $450 \mathrm{~W}$ xenon lamp as the excitation source. The FTIR spectra were recorded on a Nexus 912 AO446 spectrophotometer. The morphology and microstructure of the CQDs were examined by high-resolution transmission electron microscopy (HRTEM) on a Philips Tecnai G2 F30 microscope (Philips, The Netherlands) with an accelerating voltage of $200 \mathrm{kV}$. The UV absorption of the samples was measured with UV-vis spectrophotometer Lambda 750 from PerkinElmer. The interaction between the elements of the CQDs were determined with PHI-5000 X-ray photoelectric spectrometry (XPS). ${ }^{1} \mathrm{H}$ NMR spectra of the samples were measured with Ascend 400 spectrometer with $\mathrm{D}_{2} \mathrm{O}$ and deuterated chloroform as solvent.

\subsection{Experimental Methods}

\subsubsection{Synthesis of CQDs and CQDs@Ln (TFA) 3}

The CQDs are synthesized according to the reported procedure [12,33] as follows: citric acid (1.0 g) and urea $(2.0 \mathrm{~g})$ is reacted at $160{ }^{\circ} \mathrm{C}$ for $6 \mathrm{~h}$ in DMF $(10 \mathrm{~mL})$. NaOH aqueous solution $\left(50 \mathrm{mg} \cdot \mathrm{mL}^{-1}\right.$, $20 \mathrm{~mL}$ ) is mixed with the obtained solution when cooling to room temperature, and then centrifuged for $15 \mathrm{~min}$. Immediately after the precipitate is dissolved in dilute $\mathrm{HCl}$ aqueous solution $(5 \%, 20 \mathrm{~mL})$ and stirred for $10 \mathrm{~min}$, and then centrifuged again at 16,000 $\mathrm{r} \mathrm{min}^{-1}$ for $15 \mathrm{~min}$. The precipitate is collected, dissolved in water and centrifuged $\left(16,000 \mathrm{r} \mathrm{min}^{-1}, 15 \mathrm{~min}\right)$ twice.

CQDs@Ln $(\mathrm{TFA})_{3}$ is obtained based on the combination of covalent bonds in Scheme 1. CQDs powder $50 \mathrm{mg}$ obtained above, trifluoroacetylacetone (TFA) $(1.5 \mathrm{mmol})$ and $\mathrm{NaOH}(1.5 \mathrm{mmol})$ were dissolved in $15 \mathrm{~mL}$ of absolute ethanol, reacted at $60{ }^{\circ} \mathrm{C}$ for $2 \mathrm{~h}$. Then added $\mathrm{LnCl}_{3} \cdot 6 \mathrm{H}_{2} \mathrm{O}$ $(\mathrm{Ln}=\mathrm{Eu}, \mathrm{Tb}) 0.5 \mathrm{mmol}$ to continue the reaction for $3 \mathrm{~h}$. The mixture solution is cooled with ice water and suction filtered, and then the product was dried in an oven at $50{ }^{\circ} \mathrm{C}$ for $12 \mathrm{~h}$.

\subsubsection{Preparation of White-Light CQDs@Eu/Tb $(\mathrm{TFA})_{3}$}

Typically, white light source is composed of red, green and blue primary colors. Herein, CQDs@Eu/Tb $(\mathrm{TFA})_{3}$ hybrid material with three luminous centers was successfully prepared via introducing Ln (TFA) 3 $\left(\mathrm{Eu}^{3+}: \mathrm{Tb}^{3+}=1: 1\right)$ into the aqueous solution of CQDs. Subsequently, a mixed solution with white light emission is obtained by adjusting the emission spectrum of the hybrid material at different excitation wavelengths. Moreover, white light can be obtained by adjusting the ratio of different lanthanide complexes at the same excitation wavelength.

\subsubsection{Chemical Sensing Experiment of CQDs@Tb (TFA) 3}

CQDs@Tb $(\mathrm{TFA})_{3}$ used to detect a series of metal anions $\left(\mathrm{CO}_{3}{ }^{2-}, \mathrm{NO}_{3}{ }^{-}, \mathrm{S}_{2} \mathrm{O}_{8}{ }^{2-}, \mathrm{SO}_{4}{ }^{2-}, \mathrm{I}^{-}\right.$, $\left.\mathrm{Br}^{-}, \mathrm{CL}^{-}, \mathrm{CrO}_{4}{ }^{2-}, \mathrm{Cr}_{2} \mathrm{O}_{7}{ }^{2-}, \mathrm{MnO}_{4}{ }^{-}\right)$at room temperature. CQDs@Tb (TFA) 3 powders (3.0 mg) were dissolved in different anionic aqueous solutions $(3 \mathrm{~mL})$. Then, the mixtures were dispersed by ultrasound system, and then fluorescence measurements taken.

Measure the different concentration of $\mathrm{Cr}_{2} \mathrm{O}_{7}{ }^{2-}, \mathrm{CrO}_{4}{ }^{2-}$ and $\mathrm{MnO}_{4}{ }^{-}$was similar to the ways described above. Configure different concentrations of $\mathrm{Cr}_{2} \mathrm{O}_{7}{ }^{2-}, \mathrm{CrO}_{4}{ }^{2-}$ and $\mathrm{MnO}_{4}{ }^{-}$aqueous solution: $0-50 \mu \mathrm{M}$. 


\section{Conclusions}

In summary, we have successfully synthesized a novel lanthanide functional carbon quantum dots dual emission fluorescent composite CQDs@Ln $(\mathrm{TFA})_{3}(\mathrm{Ln}=\mathrm{Eu}, \mathrm{Tb})$ by introducing the lanthanide complex $\operatorname{Ln}(\mathrm{TFA})_{3}$ into the surface of CQDs with the carboxyl group. The as-synthesized hybrids showed excellent photoluminescence properties with the application in the chemical-sensing and photocatalytic field. The intense white emission can be obtained with the excitation wavelength at $350 \mathrm{~nm}$. Moreover, CQDs@Tb (TFA) ${ }_{3}$ can be used to selectively detect $\mathrm{MnO}_{4}{ }^{-}$in aqueous solution with the linear range from $0-50 \mu \mathrm{M}$. It can be drawn a conclusion that the lanthanide functionalized CQDs have potential application in photocatalytic water decomposition and further detect the residue of photocatalytic materials in water due to the special photoluminescence properties and sensing performance.

Supplementary Materials: The following are available online at http://www.mdpi.com/2073-4344/10/8/833/s1. Figure S1 PL spectra of the CQDs: (a) different excitation wavelengths in ethanol solution (b) optimal excitation and emission spectra; Figure S2 (a) XPS spectra (b) O1 s of CQDs and CQDs@Ln (TFA)3; Figure S3 Raman spectra of CQDs and CQDs@Tb (TFA)3; Figure S4 Interference experiment: MnO4-,CrO42- and Cr2O72- of CQDs@Tb (TFA)3; Figure S5 The emission spectrum of CQDs@Eu (TFA)3 at different concentrations of $\mathrm{MnO}_{4}{ }^{-}$.

Author Contributions: Conceptualization, F.-R.Z., S.-N.W. and Y.L.; investigation, F.-R.Z., F.-F.W. and D.L.; writing—original draft, S.-N.W. and F.-R.Z.; supervision and review, Y.L. All authors have read and agreed to the published version of the manuscript.

Funding: This work was supported by the National Natural Science Foundation of China $(21101107,51173107)$; State Key Laboratory of Pollution Control and Resource Reuse Foundation (NO. PCRRF19017).

Acknowledgments: The authors wish to acknowledge State Key Laboratory of Molecular Engineering of polymers (Fudan University), The Staff Members of the Electron Microscopy System at the National Facility for Protein Science in Shanghai (NFPS, Zhangjiang Lab).

Conflicts of Interest: There are no conflicts to declare.

\section{References}

1. Wang, Q.; Zhang, S.; Zhong, Y.; Yang, X.-F.; Li, Z.; Li, H. Preparation of yellow-green-emissive carbon dots and their application in constructing a fluorescent turn-on nanoprobe for imaging of selenol in living cells. Anal. Chem. 2017, 89, 1734-1741. [CrossRef] [PubMed]

2. Fu, P.; Zhou, L.; Tang, L.; Cai, X.; Yuan, Y. Progress in preparation of carbon quantum dots and its application in the fields of energy and environment. Chin. J. Appl. Chem. 2016, 33, 742-755.

3. Wu, X.; Zhao, B.; Zhang, J.; Xu, H.; Xu, K.; Chen, G. Photoluminescence and photodetecting properties of the hydrothermally synthesized nitrogen-doped carbon quantum dots. J. Phys. Chem. C 2019, 123, 25570-25578. [CrossRef]

4. Zhao, Y.Y.; Qu, S.N.; Feng, X.Y.; Xu, J.C.; Yang, Y.; Su, S.C.; Wang, S.P.; Ng, K.W. Tailoring the photoluminescence excitation dependence of the carbon dots via an alkali treatment. J. Phys. Chem. Lett. 2019, 10, 4596-4602. [CrossRef] [PubMed]

5. Ding, H.; Wei, J.-S.; Zhong, N.; Gao, Q.-Y.; Xiong, H.-M. Highly efficient red-emitting carbon dots with gram-scale yield for bioimaging. Langmuir 2017, 33, 12635-12642. [CrossRef] [PubMed]

6. Ray, S.; Saha, A.; Jana, N.R.; Sarkar, R. Fluorescent carbon nanoparticles: Synthesis, characterization, and bioimaging application. J. Phys. Chem. C 2009, 113, 18546-18551. [CrossRef]

7. Cao, L.; Wang, X.; Meziani, M.J.; Lu, F.; Wang, H.; Luo, P.G.; Lin, Y.; Harruff, B.A.; Veca, L.M.; Murray, D. Carbon dots for multiphoton bioimaging. J. Am. Chem. Soc. 2007, 129, 11318-11319. [CrossRef]

8. Zhu, S.; Meng, Q.; Wang, L.; Zhang, J.; Song, Y.; Jin, H.; Zhang, K.; Sun, H.; Wang, H.; Yang, B. Highly photoluminescent carbon dots for multicolor patterning, sensors, and bioimaging. Angew. Chem. Int. Ed. 2013, 52, 3953-3957. [CrossRef]

9. Hola, K.; Zhang, Y.; Wang, Y.; Giannelis, E.P.; Zboril, R.; Rogach, A.L. Carbon dots—Emerging light emitters for bioimaging, cancer therapy and optoelectronics. Nano Today 2014, 9, 590-603. [CrossRef]

10. Zheng, X.T.; Ananthanarayanan, A.; Luo, K.Q.; Chen, P. Glowing graphene quantum dots and carbon dots: Properties, syntheses, and biological applications. Small 2015, 11, 1620-1636. [CrossRef] 
11. Li, Q.; Ohulchanskyy, T.Y.; Liu, R.; Koynov, K.; Wu, D.; Best, A.; Kumar, R.; Bonoiu, A.; Prasad, P.N. Photoluminescent carbon dots as biocompatible nanoprobes for targeting cancer cells in vitro. J. Phys. Chem. C 2010, 114, 12062-12068. [CrossRef]

12. Li, D.; Jing, P.; Sun, L.; An, Y.; Shan, X.; Lu, X.; Zhou, D.; Han, D.; Shen, D.; Zhai, Y. Near-infrared excitation/emission and multiphoton-induced fluorescence of carbon dots. Adv. Mater. 2018, 30, 1705913. [CrossRef] [PubMed]

13. Yao, H.; Zhao, W.; Zhang, S.; Guo, X.; Li, Y.; Du, B. Dual-functional carbon dot-labeled heavy-chain ferritin for self-targeting bio-imaging and chemo-photodynamic therapy. J. Mater. Chem. B 2018, 6, 3107-3115. [CrossRef] [PubMed]

14. Dong, R.; Li, Y.; Li, W.; Zhang, H.; Liu, Y.; Ma, L.; Wang, X.; Lei, B. Recent developments in luminescent nanoparticles for plant imaging and photosynthesis. J. Rare Earths 2019, 37, 903-915. [CrossRef]

15. Mirtchev, P.; Henderson, E.J.; Soheilnia, N.; Yip, C.M.; Ozin, G.A. Solution phase synthesis of carbon quantum dots as sensitizers for nanocrystalline TiO2 solar cells. J. Mater. Chem. 2012, 22, 1265-1269. [CrossRef]

16. Tang, Q.; Zhu, W.; He, B.; Yang, P. Rapid conversion from carbohydrates to large-scale carbon quantum dots for all-weather solar cells. ACS Nano 2017, 11, 1540-1547. [CrossRef]

17. Yu, H.; Zhao, Y.; Zhou, C.; Shang, L.; Peng, Y.; Cao, Y.; Wu, L.-Z.; Tung, C.-H.; Zhang, T. Carbon quantum dots $/ \mathrm{TiO}_{2}$ composites for efficient photocatalytic hydrogen evolution. J. Mater. Chem. A 2014, 2, 3344-3351. [CrossRef]

18. Fei, H.; Ye, R.; Ye, G.; Gong, Y.; Peng, Z.; Fan, X.; Samuel, E.L.; Ajayan, P.M.; Tour, J.M. Boron-and nitrogen-doped graphene quantum dots/graphene hybrid nanoplatelets as efficient electrocatalysts for oxygen reduction. ACS Nano 2014, 8, 10837-10843. [CrossRef]

19. Wang, R.; Lu, K.-Q.; Tang, Z.-R.; Xu, Y.-J. Recent progress in carbon quantum dots: Synthesis, properties and applications in photocatalysis. J. Mater. Chem. A 2017, 5, 3717-3734. [CrossRef]

20. Sakdaronnarong, C.; Sangjan, A.; Boonsith, S.; Kim, D.C.; Shin, H.S. Recent developments in synthesis and photocatalytic applications of carbon dots. Catalysts 2020, 10, 320. [CrossRef]

21. He, J.; Zhang, H.; Zou, J.; Liu, Y.; Zhuang, J.; Xiao, Y.; Lei, B. Carbon dots-based fluorescent probe for "off-on" sensing of $\mathrm{Hg}$ (II) and $\mathrm{I}^{-}$. Biosens. Bioelectron. 2016, 79, 531-535. [CrossRef]

22. Mondal, T.K.; Ghorai, U.K.; Saha, S.K. Dual-emissive carbon quantum dot-Tb nanocomposite as a fluorescent indicator for a highly selective visual detection of $\mathrm{Hg}$ (II) in water. ACS Omega 2018, 3, 11439-11446. [CrossRef] [PubMed]

23. Mondal, T.K.; Gupta, A.; Shaw, B.K.; Mondal, S.; Ghorai, U.K.; Saha, S.K. Highly luminescent N-doped carbon quantum dots from lemon juice with porphyrin-like structures surrounded by graphitic network for sensing applications. RSC Adv. 2016, 6, 59927-59934. [CrossRef]

24. Bhattacharyya, S.; Konkena, B.; Jayaramulu, K.; Schuhmann, W.; Maji, T.K. Synthesis of nano-porous carbon and nitrogen doped carbon dots from an anionic MOF: A trace cobalt metal residue in carbon dots promotes electrocatalytic ORR activity. J. Mater. Chem. A 2017, 5, 13573-13580. [CrossRef]

25. Jiang, K.; Wang, Y.; Cai, C.; Lin, H. Conversion of carbon dots from fluorescence to ultralong room-temperature phosphorescence by heating for security applications. Adv. Mater. 2018, 30, 1800783. [CrossRef] [PubMed]

26. Wang, Z.; Yuan, F.; Li, X.; Li, Y.; Zhong, H.; Fan, L.; Yang, S. 53\% efficient red emissive carbon quantum dots for high color rendering and stable warm white-light-emitting diodes. Adv. Mater. 2017, 29, 1702910. [CrossRef]

27. Zhang, F.; Feng, X.; Zhang, Y.; Yan, L.; Yang, Y.; Liu, X. Photoluminescent carbon quantum dots as a directly film-forming phosphor towards white LEDs. Nanoscale 2016, 8, 8618-8632. [CrossRef]

28. Yuan, F.; Wang, Y.-K.; Sharma, G.; Dong, Y.; Zheng, X.; Li, P.; Johnston, A.; Bappi, G.; Fan, J.Z.; Kung, H. Bright high-colour-purity deep-blue carbon dot light-emitting diodes via efficient edge amination. Nat. Photonics 2020, 14, 171-176. [CrossRef]

29. Singh, V.K.; Singh, V.; Yadav, P.K.; Chandra, S.; Bano, D.; Kumar, V.; Koch, B.; Talat, M.; Hasan, S.H. Bright-blue-emission nitrogen and phosphorus-doped carbon quantum dots as a promising nanoprobe for detection of $\mathrm{Cr}$ (vi) and ascorbic acid in pure aqueous solution and in living cells. New J. Chem. 2018, 42, 12990-12997. [CrossRef]

30. Liu, Y.; Zhou, L.; Li, Y.; Deng, R.; Zhang, H. Highly fluorescent nitrogen-doped carbon dots with excellent thermal and photo stability applied as invisible ink for loading important information and anti-counterfeiting. Nanoscale 2017, 9, 491-496. [CrossRef] 
31. Hoan, B.T.; Thanh, T.T.; Tam, P.D.; Trung, N.N.; Cho, S.; Pham, V.-H. A green luminescence of lemon derived carbon quantum dots and their applications for sensing of $\mathrm{V}^{5+}$ ions. Mater. Sci. Eng. B 2019, 251, 114455. [CrossRef]

32. Liu, Y.; Luo, S.; Wu, P.; Ma, C.; Wu, X.; Xu, M.; Li, W.; Liu, S. Hydrothermal synthesis of green fluorescent nitrogen doped carbon dots for the detection of nitrite and multicolor cellular imaging. Anal. Chimica Acta 2019, 1090, 133-142. [CrossRef] [PubMed]

33. Qu, S.; Zhou, D.; Li, D.; Ji, W.; Jing, P.; Han, D.; Liu, L.; Zeng, H.; Shen, D. Toward efficient orange emissive carbon nanodots through conjugated sp2-domain controlling and surface charges engineering. Adv. Mater. 2016, 28, 3516-3521. [CrossRef]

34. Ding, H.; Yu, S.-B.; Wei, J.-S.; Xiong, H.-M. Full-color light-emitting carbon dots with a surface-state-controlled luminescence mechanism. ACS Nano 2015, 10, 484-491. [CrossRef] [PubMed]

35. Zheng, K.; Li, X.; Chen, M.; Gong, Y.; Tang, A.; Wang, Z.; Wei, Z.; Guan, L.; Teng, F. Controllable synthesis highly efficient red, yellow and blue carbon nanodots for photo-luminescent light-emitting devices. Chem. Eng. J. 2020, 380, 122503. [CrossRef]

36. Liu, Y.; Chao, D.; Zhou, L.; Li, Y.; Deng, R.; Zhang, H. Yellow emissive carbon dots with quantum yield up to 68.6\% from manganese ions. Carbon 2018, 135, 253-259. [CrossRef]

37. Gao, X.; Gong, X.; Nguyen, T.T.; Du, W.; Chen, X.; Song, Z.; Chai, R.; Guo, M. Luminescent materials comprised of wood-based carbon quantum dots adsorbed on a $\mathrm{Ce}_{0.7} \mathrm{Zr}_{0.3} \mathrm{O}_{2}$ solid solution: Synthesis, photoluminescence properties, and applications in light-emitting diode devices. J. Mater. Sci. 2019, 54, 14469-14482. [CrossRef]

38. Zhu, X.; Pang, X.; Zhang, Y.; Yao, S. Titanium carbide MXenes combined with red-emitting carbon dots as a unique turn-on fluorescent nanosensor for label-free determination of glucose. J. Mater. Chem. B 2019, 7, 7729-7735. [CrossRef]

39. Jia, H.; Wang, Z.; Yuan, T.; Yuan, F.; Li, X.; Li, Y.; Tan, Z.A.; Fan, L.; Yang, S. Electroluminescent warm white light-emitting diodes based on passivation enabled bright red bandgap emission carbon quantum dots. Adv. Sci. 2019, 6, 1900397-1900405. [CrossRef]

40. Yuan, F.; Xi, Z.; Shi, X.; Li, Y.; Li, X.; Wang, Z.; Fan, L.; Yang, S. Ultrastable and low-threshold random lasing from narrow-bandwidth-emission triangular carbon quantum dots. Adv. Opt. Mater. 2019, 7, 1801202. [CrossRef]

41. Yuan, F.; Yuan, T.; Sui, L.; Wang, Z.; Xi, Z.; Li, Y.; Li, X.; Fan, L.; Tan, Z.A.; Chen, A. Engineering triangular carbon quantum dots with unprecedented narrow bandwidth emission for multicolored LEDs. Nat. Commun. 2018, 9, 1-11. [CrossRef] [PubMed]

42. Yuan, F.; He, P.; Xi, Z.; Li, X.; Li, Y.; Zhong, H.; Fan, L.; Yang, S. Highly efficient and stable white LEDs based on pure red narrow bandwidth emission triangular carbon quantum dots for wide-color gamut backlight displays. Nano Res. 2019, 12, 1669-1674. [CrossRef]

43. Yan, B. Lanthanide-functionalized metal-organic framework hybrid systems to create multiple luminescent centers for chemical sensing. Acc. Chem. Res. 2017, 50, 2789-2798. [CrossRef] [PubMed]

44. Chen, Q.; Zhu, P.; Xiong, J.; Gao, L.; Tan, K. A new dual-recognition strategy for hybrid ratiometric and ratiometric sensing perfluorooctane sulfonic acid based on high fluorescent carbon dots with ethidium bromide. Spectrochim. Acta Part A Mol. Biomol. Spectrosc. 2020, 224, 117362. [CrossRef] [PubMed]

45. Wu, J.-X.; Yan, B. A dual-emission probe to detect moisture and water in organic solvents based on green- $\mathrm{Tb}^{3+}$ post-coordinated metal-organic frameworks with red carbon dots. Dalton Trans. 2017, 46, 7098-7105. [CrossRef]

46. Chen, L.; Gao, Z.; Li, Y. Immobilization of Pd (II) on MOFs as a highly active heterogeneous catalyst for Suzuki-Miyaura and Ullmann-type coupling reactions. Catal. Today 2015, 245, 122-128. [CrossRef]

47. Dang, H.X.; Li, Y.; Zou, H.; Liu, S.H. Tunable White-light Emission Hybrids Based on Lanthanide Complex Functionalized Poly (Ionic Liquid): Assembly and Chemical Sensing. Dyes Pigment. 2020, 172, 107804. [CrossRef]

48. Zeng, Y.C.; Qiu, B.W.; Wang, F.F.; Zhou, L.; Li, Y. Transparent films based on functionalized Poly(ionic liquids) coordinating to photoactive Lanthanide $\left(\mathrm{Eu}^{3+}, \mathrm{Tb}^{3+}\right)$ and Poly(methyl methacrylate): Luminescence and chemical sensing. Opt. Mater. 2020, 107, 110149. [CrossRef] 
49. Wu, J.-X.; Yan, B. Eu (III)-functionalized In-MOF (In (OH) bpydc) as fluorescent probe for highly selectively sensing organic small molecules and anions especially for $\mathrm{CHCl}_{3}$ and $\mathrm{MnO}_{4}{ }^{-}$. J. Colloid Interface Sci. 2017, 504, 197-205. [CrossRef]

50. Wang, Y.N.; Wang, S.D.; Gao, Y.M.; Yang, L.L.; Xie, L.X. 3D cadmium (II)-based coordination polymer constructed from v-shaped semirigid ligand: Selective detection of oxoanion pollutants $\mathrm{CrO}_{4}{ }^{2-}, \mathrm{Cr}_{2} \mathrm{O}_{7}{ }^{2-}$, $\mathrm{MnO}_{4}{ }^{-}$in Water. Zeitschrift für Anorganische und Allgemeine Chemie 2019, 645, 1358-1364. [CrossRef]

51. Li, B.; Zhou, J.; Bai, F.; Xing, Y. Lanthanide-organic framework based on a 4, 4-(9, 9-dimethyl-9H-fluorene-2, 7-diyl) dibenzoic acid: Synthesis, structure and fluorescent sensing for a variety of cations and anions simultaneously. Dyes Pigment. 2020, 172, 107862. [CrossRef]

52. Shi, J.L.; Xu, P.; Wang, X.G.; Ding, B.; Zhao, X.J.; Yang, E.C. A dual-responsive luminescent terbium (III) chain for selective sensing of $\mathrm{Fe}^{3+}$ and $\mathrm{MnO}_{4}{ }^{-}$Ions. Zeitschrift für Anorganische und Allgemeine Chemie 2018, 644, 1598-1606. [CrossRef]

(C) 2020 by the authors. Licensee MDPI, Basel, Switzerland. This article is an open access article distributed under the terms and conditions of the Creative Commons Attribution (CC BY) license (http://creativecommons.org/licenses/by/4.0/). 